\title{
UIAA Medical Commission Recommendations for Mountaineers, Hillwalkers, Trekkers, and Rock and Ice Climbers with Diabetes
}

\author{
David Hillebrandt, ${ }^{1,2}$ Anil Gurtoo, ${ }^{1,3}$ Thomas Kupper, ${ }^{1,4}$ Paul Richards, ${ }^{5}$ \\ Volker Schöffl, ${ }^{1,6-8}$ Pankaj Shah, ${ }^{9}$ Rianne van der Spek, ${ }^{1,10}$ Nikki Wallis, ${ }^{11}$ and Jim Milledge ${ }^{1,12,13}$
}

\begin{abstract}
Hillebrandt, David, Anil Gurtoo, Thomas Kupper, Paul Richards, Volker Schöffl, Pankaj Shah, Rianne van der Spek, Nikki Wallis, and Jim Milledge. UIAA Medical Commission recommendations for mountaineers, hillwalkers, trekkers, and rock and ice climbers with diabetes. High Alt Med Biol 00:000-000, 2018.—The object of this advice article is not only to give the diabetic mountaineer general guidance but also to inform his or her medical team of practical aspects of care that may not be standard for nonmountaineers. The guidelines are produced in seven sections. The first is an introduction to the guidelines, and the second is an introduction to this medical problem and is designed to be read and understood by diabetic patients and their companions. The third section is for use in an emergency in mountains. The fourth is for rock, ice, and competition climbers operating in a less remote environment. These initial sections are deliberately written in simple language. The fifth and sixth sections are written for clinicians and those with skills to read more technical information, and the seventh looks at modern technology and its pros and cons in diabetes management in a remote area. Sections One and Two could be laminated and carried when in the mountains, giving practical advice.
\end{abstract}

Keywords: climbing; diabetes; mountaineering; high altitude; insulin; glucose

\section{Section One: Introduction}

W ITH THE INCREASING NUMBER of people enjoying their recreation in the mountains and the global increase in the incidence of diabetes, it is inevitable that more people with diabetes will be venturing into remote areas and to high altitude. This can only be beneficial in terms of increasing their personal fitness, which will ultimately help lower average glucose readings for the vast majority. It is sad to note that in some countries, clinicians are reluctant to encourage their patients with diabetes from going to altitude on the grounds that hypoglycemia (low blood sugar) may be confused with acute mountain sickness (AMS). Recent work has shown no increase in the incidence of AMS in well-controlled insulin-dependent diabetics on Mount Kilimanjaro using a formal daily checklist (Mustafa et al., 2015). In other countries, clinicians take a more enlightened attitude that, with good self-management and education, diabetic patients should be able to enjoy all aspects of

\footnotetext{
${ }^{1}$ Union Internationale des Associations d'Alpinisme Medical Commission (UIAA MedCom), Bern, Switzerland.

${ }^{2}$ Derriton House, Holsworthy, England.

${ }^{3}$ Department of Medicine, Lady Hardinge Medical College and Associated SSK Hospital, New Delhi, India.

${ }^{4}$ Institute of Occupational and Social Medicine, RWTH Aachen University, Aachen, Germany.

${ }^{5}$ Faculty of PreHospital Care, Basildon and Brentwood CCG, Essex, England.

${ }^{6}$ Section Sportsmedicine, Department of Trauma and Orthopedic Surgery, Klinikum Bamberg, Bamberg, Germany.

${ }^{7}$ Department of Trauma Surgery, University of Erlangen-Nuermebrg, Germany.

${ }^{8}$ Section of Wilderness Medicine, Department of Emergency Medicine, University of Colorado School of Medicine, Denver, Colorado.

${ }^{9}$ Division of Endocrinology, Mayo Clinic, Rochester, Minnesota.

${ }^{10}$ Department of Endocrinology and Metabolism, University of Amsterdam, Academic Medical Center, Amsterdam, The Netherlands.

${ }^{11}$ Emergency Department, Ysbyty Gwynedd, Bangor, Wales.

${ }^{12}$ Northwick Park Hospital, Harrow, United Kingdom.

${ }^{13}$ Department of Medicine, Medical Research Council, United Kingdom.
}

(C) David Hillebrandt et al. 2018; Published by Mary Ann Liebert, Inc. This Open Access article is distributed under the terms of the Creative Commons Attribution Noncommercial License (http://creativecommons.org/licenses/by-nc/4.0/) which permits any noncommercial use, distribution, and reproduction in any medium, provided the original author(s) and the source are cited. 
mountaineering. Diabetics have to learn to be skilled in self-care when in a remote area far from help.

The key to diabetes self-care is to have knowledge of one's condition. In the absence of the body's normal complex monitoring and feedback systems, a type 1 diabetic patient has to learn to "Think like a Pancreas" with glucose monitoring and the diabetic mountaineer's brain taking on this complex physiological role. This can be a problem with the hypoxia of altitude, where experience is so vital for all skills to be practiced safely. Diabetes self-care demands a combination of theoretical knowledge with practical skills. Mountaineering demands a specific skill set backed up by knowledge and experience. In the mountaineer with diabetes, both skill sets have to be equally developed and this can take time. Groups such as pilgrims going to altitude will be at particularly high risk since they are likely to have no previous altitude experience and they may not have a very sophisticated understanding of their diabetes in relation to unaccustomed exercise (Ganie et al., 2012).

\section{Section Two: Understanding Diabetes, Primarily for the Layman}

\section{Definition}

Diabetes is a chronic illness where the body has lost its ability to control the level of glucose in the blood (blood glucose $[\mathrm{BG}]$ ).

The BG is normally controlled by a hormone called insulin produced by a gland called the pancreas located in the abdomen.

Glucose is vital as a fuel source for the body, so too little glucose (hypoglycemia or "Hypo") can sometimes result in a fairly rapid progression to unconsciousness and, in a remote area, death, although normally warning signs appear before deterioration. Too much glucose (hyperglycemia) can act as a poison and upset the chemical and fluid balance in the body (metabolic ketoacidosis), also leading to illness, and later, unconsciousness progressing to death. Testing BG levels can guide a person to take early steps to prevent and treat these serious complications.

\section{Types of diabetes}

There are two main types of diabetes:

Type 1 diabetes occurs when the body ceases to produce its own insulin. This normally occurs in young and often fit people and can only be treated by the administration of insulin by injection. Insulin is a protein, so if taken by mouth, it would be destroyed by stomach acid and therefore would not work. Patients normally inject insulin themselves under the skin (subcutaneously [s.c.]). Some may rely on twice-daily injections, but many have up to four daily premeal injections of short-acting insulin plus one or two daily injections of long-acting background insulin. They may use additional doses for fine-tuning. Another modern system uses a continuous s.c. pump infusion of very short-acting insulin and is obviously reliant on working technology and batteries.

Soluble (short acting) insulin works quickly, but only for a short period, and is useful for "fine-tuning" BG levels in an emergency. It can be given s.c. or intramuscularly (i.m.), or occasionally, intravenously (i.v.) if under the guidance of a medical practitioner.

Type 2 diabetes normally occurs in older, often obese patients. In this case, the body cannot produce sufficient in- sulin and treatment is by diet, weight loss, and medicines (tablets and injections) that force the body to maximize its own insulin production or improve insulin's action. Sometimes a patient may use a combination of insulin and noninsulin therapies.

Rarer forms of diabetes do exist, but in practical terms can be considered to respond as either type 1 or type 2 .

All types of diabetes require careful balancing of sugar and food intake with exercise as a major part of the treatment.

If $\mathrm{BG}$ levels increase under severe physiological stress (unaccustomed exercise levels, altitude, cold, infection, diarrhea and vomiting, or injury), a type 2 diabetic may need insulin treatment. This could be relevant in a very remote area where a case of undiagnosed diabetes can be unmasked by the physiological stress of an expedition (rare).

\section{Prevention of problems}

Most people with a good understanding of their wellcontrolled diabetes should be able to experience the pleasures of the mountains just as those without diabetes. However, there are some constraints. To prevent the immediate dangers of diabetes (hypoglycemia or hyperglycemia, too little or too much sugar in the blood), patients have to balance their diet, exercise, and medication. Experienced individuals are often very skilful at this. It is particularly important that diabetics gradually build up their mountaineering experience and confidence since they not only have to learn the mountain skills but also additional skills to cope with their diabetic control. They need a good idea of the day's route plan and may need slightly longer stops than others to enable them to monitor their condition. This becomes especially true in adverse weather when a group shelter/Kisu/bothy bag can be invaluable. Any experienced mountaineering diabetic should be able to tell you how quickly their BG will drop for every half hour of ascent with or without a rucksack. This makes planning much easier.

Personal self-care skills and confidence can be built by contact with other active experienced mountaineering diabetics. The following website may be recommended: www.mountainmad.org.uk All diabetics should share knowledge of their condition with their leader, their group, and their peers. They should educate them about their condition and show where monitoring and treatment equipment are kept.

Experienced diabetics should have had medical advice regarding meals and insulin needs on long haul flights crossing time zones and when travelling. They should always carry spare food and insulin in their cabin baggage and day bag with a doctor's letter for security staff, explaining this need. They should avoid injecting their premeal short-/rapidacting insulin until their meals are served to them by waiters or airline staff in case of unexpected delays.

Alcohol, hypothermia, and exhaustion can lower BG in anybody. This is obviously even more relevant for a mountaineer with diabetes.

People who have had diabetes for many years may have long-term damage to the very small blood vessels (arterioles, capillaries, and venules) throughout the body and to the nerves to the feet (peripheral neuropathy). In the feet and hands, this may make them more prone to frostbite and infection in the event of any tissue injury. In the eyes, diabetic retinopathy (damage to the blood vessels and nerves of the eye) may be affected by altitude and puts the patient at much 
higher risk of sudden loss of sight due to retinal hemorrhage. Consequently, anybody with diabetes going above $4500 \mathrm{~m}$ must have a retinal eye check and any required treatment before departure.

If a type 1 diabetic becomes ill and stops eating, his/her insulin MUST NOT BE STOPPED. The body still needs insulin, but the amount may differ and constant monitoring of BG may be needed with frequent dose adjustment.

Individuals with type 2 diabetes receiving insulin therapy may still have the capacity to manufacture significant amounts of their own insulin. If they are not eating, then a number of these individuals may be able to manage their BG without the need for insulin, but this can only be determined by close monitoring and stepwise insulin dose adjustment.

\section{Equipment and drugs}

All diabetics should have discussed their condition with group members. They should also carry clear identification such as a medical alert talisman giving details of their medical condition. It would be sensible for them to demonstrate their equipment to their companions and indicate where it will be carried when in the mountains (and where spares will be kept). They must have worked out a tried and tested personal system before departure to keep their BG testing strips at working temperature $\left(14^{\circ} \mathrm{C}-30^{\circ} \mathrm{C}\right)$ and also a way of ensuring their insulin supplies do not get too hot, or worse, freeze. Their personal system must work in all temperatures and all weathers. This may mean they have adapted their clothing and sleeping insulation. Some will have fitted extra zips to their clothing for access to injection sites and some will modify their inner gloves to facilitate access to finger tips for BG testing. Pockets can be sewn into sleeping bags, so mountaineers can sleep with their insulin stock.

Type 1 diabetics in local mountains with established rescue facilities should consider carrying the following:

- Supplies of their normal insulin(s) with spares.

- Syringe and needles or an automatic "pen" injection device or infusion pump (with spare).

- A BG measuring system (with spare batteries and test strips).

- A fast-acting form of easily absorbed sugar (e.g., sugar, glucose tablets, jelly babies, and sweets).

- Glucose gel (e.g. "GlucoGel").

- Injectable glucagon kit.

- Reagent blood or urine strips to test for ketones.

- Spare "complex carbohydrates" such as cake, sandwiches, or muesli bars.

A type 2 diabetic in local mountains with established rescue facilities should consider carrying the following:

- Normal tablet medication with spares.

- A fast-acting form of easily absorbed sugar (e.g., sugar, glucose tabs, sweets, and gel).

- Spare food.

- A simple BG monitoring system.

If on an expedition in a remote area, in addition to the above, type 1 diabetics should carry the following:

- Additional soluble insulin or insulin Lispro/Aspart/ Glulisine.

- Additional personal antibiotics.
- Possibly consider bringing $2-3 \mathrm{~L}$ of i.v. fluid $(0.9 \%$ normal saline) with needles and giving set.

If on an expedition in a remote area, in addition to the above, type 2 diabetics should carry the following:

- System to monitor BG levels.

- Some soluble insulin and syringes and needles in case of a worsening in their condition plus the knowledge on how to use these if required.

\section{Points to note about equipment and drugs}

Old-fashioned syringes and needles are versatile and known throughout the world. Some modern western automatic injectors and cartridges are not universally available or understood.

Battery-operated BG monitoring systems are battery dependent. Batteries run out and do not work when cold. Consider having a spare system that can be read visually in the event of a failure (e.g., Betachek; www.betachek.com) or carry extra test strips with a built-in meter ("TrueOne result" in United Kingdom and Europe, but note the testing strips are not interchangeable within Europe. It is available as Accuchek Compact Plus in the United States).

There are many BG monitoring systems available. One that has been tested to $6400 \mathrm{~m}$ is the "Roche Active System." It has not been tested above $6400 \mathrm{~m}$, but is likely to still work. Any blood glucose monitoring system should be kept warm, usually by body heat and insulation, and possibly in an insulated pocket with a chemical heat pack. Their operating temperature is normally about $10^{\circ} \mathrm{C}-40^{\circ} \mathrm{C}$; however, below $14^{\circ} \mathrm{C}$, they can give false low results and above $30^{\circ} \mathrm{C}$ false high ones.

Mountaineers on long routes may not be able to wash easily and may also prepare food without adequate hand washing. Traces of sugars can be left on the fingers and will give falsely high BG measurements. If one obtains unexpected BG readings, always wash the skin of the testing area and recheck.

Insulin storage temperatures are not as critical as originally thought, but protect when possible by keeping it close to the body or in your sleeping bag and definitely avoid letting it freeze. Friobags (www.friouk.com) aid cool storage by evaporation in hot conditions.

If sugar is needed, give it in the form that is easiest to administer. For example, if able to eat, give sweets or soft drinks backed up by longer acting more complex carbohydrates Even in a semiconscious or unconscious person, some glucose can be absorbed through the tissues that line the mouth, so glucose gel (Glucogel), jam, or honey smeared onto the gums or into the cheek pouch may help. When applied in repeated small quantities, it should not compromise the airway.

Always assume that an ill, semiconscious, or unconscious diabetic is hypoglycemic and give sugar in some way if at all possible. This could save their life and in the unlikely event of them being hyperglycemic, it would be like a "drop in the ocean" and do no harm.

Glucagon is a potential life-saving drug for an unconscious diabetic. It is given by i.m. injection, but remember absorption of any i.m./s.c. injection can be delayed in a cold patient. It kicks the body into mobilizing the last reserves of sugar from the liver and may be sufficient to bring the person around enough so they can eat and drink to complete their recovery. In 
an exhausted mountaineer, it may not work if the liver reserves are already low, which can also happen after a hard mountain day in a nondiabetic. If it is used, remember that the person must then eat lots of carbohydrate to restock the body reserves.

All used syringes, needles, finger-pricking lancets, and blood-testing strips should be regarded as medically contaminated and disposed off appropriately. Safe disposal of medical waste (BG strips, infusion cannula, infusion cannula introducers, infusion tubing, continuous glucose monitor (CGM) sensors, etc.) and sharps (finger pricking lancets, pen needles, and syringes) is also an essential consideration in the mountains. If on an extended expedition, either as a single diabetic or group of diabetics, it is wise to discuss how this will be undertaken in advance of the expedition. Needles can be safely clipped off syringes or pen needles and stored using devices such as the BD Safe-Clip ${ }^{\mathrm{TM}}$ Needle Clipping \& Storage Device, which can safely store up to 1500 needles. It is a sensible recommendation for each individual with diabetes to be responsible for their own contaminated medical waste.

Traveling through security and airports, dealing with time zones, and flying with diabetes equipment could be a whole section in itself, especially since after $9 / 11$ security, with the reduction in fluid volumes that individuals are allowed to carry in their hand luggage.

Due to complex metabolic effects, acetazolamide may enhance diabetic ketoacidosis and is not recommended for prevention of AMS in diabetics. Likewise, dexamethasone may increase insulin resistance and is not recommended for prevention of AMS. Slow ascent and acclimatization are always preferable. Both drugs could be used to treat lifethreatening High-Altitude Pulmonary Edema (HAPE) or High-Altitude Cerebral Edema (HACE) in an emergency to buy time for the essential descent, but with careful simultaneous BG monitoring.

Metformin (Prescription Only Medication [POM]), a drug used alone, with insulin or with other oral hypoglycemic agents in some diabetics may cause a chemical effect known as lactic acidosis in any situation of low oxygen concentration (e.g., altitude). It should possibly be avoided in high mountains, although case studies are limited and some authorities believe the effect is minimal.

\section{Section Three: Management of Diabetic Problems in the Mountains}

Treatment of diabetic emergencies in remote areas with rescue facilities

(1) Prevention of problems is the key at all times.

(2) Always listen to diabetic companions since they normally know their own condition best. However, a person becoming hypoglycemic can become irrational and even aggressive (as if drunk, suffering from hypothermia or HACE).

(3) Always assume that any unwell diabetic needs sugar and insist that they take sweets, glucose, or sugary drinks if you are worried about them. They may make a swift recovery and thank you.

(4) If you ever have to give rapidly absorbed sugar to a diabetic, always follow it with other forms of longer acting carbohydrate to prevent a recurrence and cease activity until a full recovery is made. Carbohydrate sources high in protein should be avoided when trying to treat or prevent hypogly- cemia. Dietary fat can also delay absorption of carbohydrates and slow the recovery from hypoglycemia.

(5) Progression to unconsciousness for a hypoglycemic diabetic (especially if cold) can be rapid. It is like watching somebody become drunk. Initially they may be a bit vague, may have slurred speech, and then loose balance and coordination. They may act out of character and become irrational before collapsing and becoming unable to walk, eventually becoming totally unconscious when they will be unable to swallow. They will lose specific, and later, nonspecific pain responses. They are now comatose and, without treatment, death will follow.

(6) Treatment is to get oral sugar/glucose into the patient as soon as possible. If they recover, self-rescue and retreat may then be a priority.

(7) If they cannot swallow, try using glucose gel (Glu$\operatorname{coGel}^{\circledR}$ ) or honey rubbed on to the gums or in the cheek pouch.

(8) If they are unconscious, you are unlikely to do any harm by giving one ampoule of glucagon (POM) by i.m. or s.c. injection. It is preferable to give this after checking and rechecking BG measurements and confirming hypoglycemia (less than $4 \mathrm{mmol} / \mathrm{L}$ or $72 \mathrm{mg} / \mathrm{dL}$ ). In really adverse weather, this may not be possible and the injection should still be given. Nausea with or without vomiting can follow injection of glucagon.

(9) Do not forget to treat any unconscious patient in line with basic first aid advice such as nursing in the recovery/coma position and insulating from the cold.

(10) If they recover after glucagon (it may take 20 minutes or more if cold) and then supplementary sugar and carbohydrates, an evacuation must be considered.

(11) If they do not recover consciousness, one is dealing with a full emergency. If possible, send details of any BG readings with the detailed message for help. It may influence the equipment and expertise brought to the scene.

It is very unlikely that you will have to deal with an unconscious hyperglycemic patient. This normally only occurs if there has been a mistake over one or more missed insulin doses, problems with interpreting BG test results, or denaturation of insulin due to storage problems. Discuss the management plan with occasional the patient and/or get expert advice or help.

\section{Remote area diabetes}

Treatment of diabetic emergencies on a remote area expedition away from rescue facilities

(1) All the principles of care in more accessible mountains with rescue facilities still apply for a hypoglycemic patient, but the decision regarding continuation of the trip for the patient becomes more complex and requires discussion once they have fully recovered.

(2) In a remote area, the risk of incidental illness such as diarrhea and vomiting or other infection is much greater. Have a low threshold for commencing antibiotics for a possible infection in a known diabetic, preferably with prior directives or experienced medical advice. Malaria 
would be a major problem requiring specific antimalarial therapy, preferably under close medical supervision.

(3) How does one diagnose a sick diabetic? Two or more high $B G$ readings above $300 \mathrm{mg} / \mathrm{dL}$ or $18 \mathrm{mmol} / \mathrm{L}$ indicate hyperglycemia, which with nausea, vomiting, diarrhea, fever, injury, or major infection is a medical emergency. If ketones are present in the urine or blood, the situation is even more serious.

(4) If in any doubt about an unwell diabetic, try to get the patient to run a high blood sugar, for example, 10$12 \mathrm{mmol} / \mathrm{L}$ or $180 \mathrm{mg} / \mathrm{dL}$. This is safer than a low BG in a remote area.

(5) In the event of vomiting, liberally use standard oral rehydration preparations. Have a low threshold for commencing supplementary therapy such as antiemetics or antibiotics for a gastrointestinal infection. Since the patient cannot eat, fluids with calories such a fruit juices should be taken.

(6) The hormones produced under physiological stress may raise the $\mathrm{BG}$ even if no food is being taken. An ill diabetic due to infection or trauma still needs insulin, but they may also need to take extra easily absorbed sugary drinks. They should monitor their BG and alter their insulin dose as needed. Never completely stop insulin even if not eating.

(7) The drug of choice for a diabetic whose BG is rising is short-acting insulin (Soluble, Lispro/Aspart/Glulisine) and they can normally administer this themselves with careful BG monitoring. This is only likely to occur in the event of intercurrent illness, trauma, or being stuck in a tent in bad weather for a prolonged period with no exercise.

(8) If a patient becomes unconscious due to hyperglycemia (high BG), they will suffer from severe dehydration and this is often the factor that can kill them. If no immediate medical help is available, seek advice through a telemedicine system such as satellite phone. This should be from a physician who not only understands diabetes but also the realities of operating in a remote and potentially hostile environment. They cannot take fluids orally, so ideally, they need intravenous fluids. We suggest $1 \mathrm{~L}$ of normal saline given over 2 hours, then another liter over 3 hours, and then any more you have left at the same rate. It could be given faster under medical supervision.

They may also need short-acting insulin by injection. This should only be given if you have three high BG readings (over $20 \mathrm{mmol} / \mathrm{L}$ or $360 \mathrm{mg} / \mathrm{dL}$ ) taken over 20 minutes. It is recommended to give 4 units of soluble insulin half hourly and take half-hourly BG readings. Two units of insulin half hourly can be given if they start to recover and the BG readings drop. This should be given at the same time as i.v. fluid is trickled into the vein. Higher insulin doses may be given by a physician.

If the patient is unable to take oral fluids and no sterile i.v. fluid is available or practical, nonsterile fluid can be given at a rate of about $1 \mathrm{~L}$ over 12 hours by the rectal route.

\section{Section Four: Rock Climbing, Ice Climbing Sport Climbing, and Competition Climbing}

There are many climbers with diabetes who are managing their condition in extreme environments and conditions with- out trouble, but caution, self-management, preparedness, and constant blood sugar monitoring are essential. The mountaineering aspects of rock climbing have already been covered in this article, so this section will look at the common disciplines of rock climbing (sport climbing, bouldering, indoor climbing, and competition climbing). For long multipitch routes or mixed alpine climbs, the recommendations and considerations (environmental aspects, cold, heat, long durations, etc.) must be combined with the specific advice in this section. For a climber with diabetes, both maximum strength and endurance may be reduced, depending on how tightly managed BG levels are and the duration of the diabetes.

\section{General aspects}

Rock climbing is a suitable sport for a diabetic if he or she is trained to manage and monitor their condition, but for toplevel performers, close sports medicine monitoring of the athlete is recommended. This monitoring needs to include the recognized potential trouble areas for a diabetic person such as cardiovascular system, feet, and eyes (Küpper et al., 2009; Küpper, 2010). Regular laboratory monitoring of renal function, $\mathrm{HbA} 1 \mathrm{c}$, and for possible proteinuria is needed. Up to $50 \%$ of those with type 2 diabetes suffer from symptomfree coronary heart disease, so a regular basic assessment of the cardiovascular system is advisable.

Any climbing partner should be informed about diabetes and trained in how to manage a hypoglycemic episode. The carbohydrate intake must be planned for longer climbs (15-30 g for every $1 / 2$ hour of physical activity (Küpper, 2010) and should be carried on the route with a BG monitoring system. Some chalk bags have small zip pockets, which are ideal for carrying this on a climb. The BG level should be maintained at a normal or high normal level and must be monitored closely before, during, and after the sporting activity. Hydration levels also need to be closely assessed, especially when climbing in warm climates.

\section{Orthopedic aspects}

The main orthopedic issues for diabetic rock climbers are possible peripheral microvascular problems or peripheral neuropathy when tight climbing footwear is used. Climbers tend to prefer tight footwear for increased sensitivity and power, on average $2-3$ sizes smaller than their standard shoe size (Killian et al., 1998; Schöffl and Winkelmann, 1999; Van de Putten and Snijder, 2001; Morrison and Schöffl, 2007; Buda et al., 2013; Schöffl and Küpper, 2013). Once accustomed to small-fitting shoes, they also have a tendency to choose overtight everyday shoes. Close-fitting climbing shoes can cause blisters, abrasions, toe nail infections, bunions, and subungual hematoma, and, in the long term, claw toes and potential hallux valgus deformity (Schöffl and Winkelmann, 1999). The long-term neuropathic and vascular complications of diabetes put the climber at increased risk of infection with associated delayed healing. Minor injuries or bruises may not be noticed due to neuropathy and thus lead to further harm. Diabetic climbers are advised to check their feet for injuries or infections at the end of every climbing day. They must be sensible when choosing their shoe size for their climbing shoes, avoiding small sizes with soft unsupportive soles and uppers. Soft specialist shoes for bouldering often have a downturn toward the toes executed through a rubber slingshot construction around the heel. Some specialist shoes are constructed in two parts, with a single front part and thinner and 
thus weaker, heel section. This gives a much more precise feel for the rock, but puts more stress on the toes and should be avoided in diabetics who may have neuropathy, vascular disease, or limitations in joint mobility/foot flexibility. Slightly stiffer shoes with a complete sole are recommended.

Microvascular and neurological complications can also affect the hands and any minor finger injuries such as cuts and flaps, which are common when climbing, must be treated promptly and appropriately.

There are no hard data available to show if a diabetic climber is at a higher risk to themselves or others due to hypoglycemic episodes when leading or belaying, but specific care should be taken if there have been significant periods of hyperglycemia or hypoglycemia in the recent past (Küpper, 2010).

\section{Ice climbing}

In cold temperatures, the stress on the toes is high. Most winter climbers have experienced the agony of the "hot aches" as fingers or toes warm up (Melvin and George, 2016). In the presence of neuropathy or vascular disease, a diabetic climber with prolonged numb toes and fingers increases the risk of unnoticed small injuries, which can later progress to infections when compared to nondiabetics. Microvascular and neuropathic numbness caused by diabetes and cold combine to cause potential problems and can also lead to frostbite, which in turn will suffer delayed healing.

The skills of the cold weather mountaineer are needed to protect insulin from freezing and keep the blood sugar testing system warm. Some of the strips are sensitive to ultraviolet light, but since they are normally stored in a light-proof container, this is not normally relevant.

\section{Competition climbing}

In competition climbing, the participating athletes have to stay in an isolation zone before they compete. These stays can last up to 6 hours and may interfere with blood sugar level regulation at a time when the body is also under psychological, physiological, and physical stress. Competing athletes with diabetes need to be confident in the management of their blood sugar and control it through all stages of the competition. The athletes should be advised to apply for a Therapeutic Use Exemption if insulin is part of their therapy (WADA, 2017).

\section{Section Five: Insulin Use for Mountaineers with Diabetes and Their Medical Advisors}

This section is adapted from an original article first published in High Altitude Medicine and Biology Journal $(H A M \& B)$ of the International Society of Mountain Medicine (ISMM) with the editor's permission (Richards and Hillebrandt, 2013) (See Appendix 1).

\section{Abstract}

With the increasing prevalence of diabetes and current social philosophy of enablement, many more diabetics are travelling to high altitude where the rate of AMS in type 1 diabetic mountaineers is no different to nondiabetics. Numerous effects of exercise, both degree and duration, dietary change, illness, stress, mountain sickness, counter-regulatory hormones, and altitude increased sympathetic output, and catecholamines have led to conflicting accounts of insulin requirement increasing or decreasing at altitude. Overall, it would appear that the effects of diet and exercise outweigh those of altitude. Good control requires continual insulin dose adjustment with frequent feedback from BG testing, but glucometers can overread or underread at altitude. In addition, heat or cold exposure can degrade insulin efficacy and strategies for storing insulin are described.

\section{Introduction}

A diabetic contemplating a mountain journey faces demanding challenges of environmental extremes of cold, heat, dry air, and hypobaric hypoxia, intense or prolonged exercise interspersed with possible episodes of low activity, dietary change, and often, depending on destination, circadian dysrhythmia, and increased risk of infectious illness. Poorly controlled diabetics are at an increased risk of dehydration (due to hyperglycemic osmotic diuresis), heat illness (Kenny et al., 2010; Yardley et al., 2013), or hypothermia (impaired thermogenesis in hypoglycemia), and any peripheral vascular or peripheral neuropathic complication increases the risk of cold injury or frostbite. Other comorbidities such as renal, coronary artery, or ocular disease add further hazard to altitude travel (Mader and Tabin, 2003; Bartsch and Gibbs, 2007; Burtscher, 2007; Wu et al., 2007; Luks et al., 2008; Milledge and Kupper, 2008; Mieske et al., 2010). Numerous physiological changes occur in all persons traveling to altitude, some of which affect glycemic control (de Mol et al., 2014; Mohajeri et al., 2015). Nevertheless, as the prevalence of diabetes is now 8.6\% in the United Kingdom (Public Health England, 2016), 9.4\% in the United States (American Diabetes Association, 2015), and anticipated to affect 366 million worldwide by 2030 (Wild et al., 2004), diabetics inevitably travel to high destinations for business, or as tourists, skiers, trekkers, or mountaineers and appear to cope reasonably well. AMS rates of type 1 diabetic mountaineers at high altitude appear to be no different to nondiabetics (Admetlla et al., 2001; Moore et al., 2001b; Pavan et al., 2003; Kalson et al., 2007).

This section focuses on the management of insulin in type 1 diabetics in the high-altitude environment. Unfortunately, as is often the case in altitude medicine, there is a paucity of studies to guide clinical practice and indeed, much of the physiological research of the effects of exercise or hypoxia on glycemic and metabolic control have been conducted on nondiabetics. The information here derives from the published literature where it exists and where it does not exist, the opinion and hypotheses of the authors are given, these being derived from their practical experience as mountaineering diabetics and advisors to a commercial mountaineering guiding company, plus the opinions of the wider mountaineering diabetic public (Mountains for Active Diabetics, 2013).

\section{Crossing time zones}

Reaching the world's greater mountain ranges often involves long-distance travel across time zones. When this occurs rapidly, for example, by air, adjustment of insulin dose is usually required. When travelling east to west, the day is effectively prolonged and an extra meal is often included, requiring extra insulin (usually fast acting). Conversely, when travelling west to east, the day is effectively shortened and the insulin dose should be reduced. Up to 2-4 hours of time difference can be tolerated by many diabetics (Chandran and Edelman, 2003; Diabetes UK, 2013) as part of the day-to- 
day $10 \%-20 \%$ intraindividual variability in insulin metabolic effect (Heinemann et al., 1998). Some diabetics prefer to continue on home-time, making adjustments to the time of taking food and insulin by 2-3 hours per day until destination time is matched. For this, a second watch with a reminder alarm is useful. Purging of air bubbles from insulin pumps is required for air travel (section Seven).

\section{Factors affecting insulin resistance}

Insulin promotes glucose transport into muscles, liver, and adipose tissue. The liver is the main organ of glucose homeostasis, producing glucose (from glycogenolysis of liver glycogen and gluconeogenesis from lactic acid, fatty acids [by glycerol], or some amino acids) in response to a lowering of BG, raised glucagon, catecholamines, and growth hormone, and taking up glucose from the blood in response to insulin to form liver glycogen, or if this is replete, fatty acids. BG level is therefore a result of the interplay of the above hormones. Travel, stress, anxiety, circadian dysrhythmia, infection, unfamiliar food, hypobaric hypoxic gastrointestinal disturbance, and AMS may all affect appetite or glycemic control.

Exercise facilitates noninsulin-dependent glucose transport into skeletal muscle by translocation of GLUT-4 transporters to the muscle cell membrane and reduces a diabetic's insulin requirement for several hours (MacDonald, 1987). Guidelines suggest that basal insulin may need reducing $10 \%-20 \%$ the night after exercise to prevent subsequent hypoglycemia, while insulin doses may need to be increased on rest days (Perry and Gallen, 2009). Upper limb exercise (Ahlborg et al., 1986) or short bursts of intense exercise (Gallen, 2005) can produce hyperglycemia due to enhanced counter-regulatory hormone response. The added effect of altitude, however, complicates as it appears that insulin requirement may increase with altitude (Pavan et al., 2003; de Mol et al., 2011), in one case producing unexpected hyperglycemia, despite markedly increased exercise with unchanged food intake or insulin (Valletta et al., 2012). The effect has been attributed to increased sympathetic activity, counter-regulatory hormones, cortisol, growth hormone, and catecholamines (Leal, 2005). After expedition, HBA1c increases in both diabetics (despite increasing insulin) and nondiabetics, suggesting that altitude has a detrimental effect on glycemic control (Pavan et al., 2004). It is possible that these changes reflect a similarity of catecholamines associated with an equal prevalence of AMS in both groups. Hyperglycemia with exercise may also represent overreduction in baseline insulin or an issue with dose timing. Reducing insulin by $50 \%$ in compensation for lower oral carbohydrate due to anorexia may have contributed to hyperglycemia and ketosis in four climbers on the Diabetes Federation of Ireland Kilimanjaro Expedition (Moore et al., 2001b). On Aconcagua Admetlla found that overall diet and exercise had a greater influence on glycemia than altitude (Admetlla et al., 2003).

Delayed gastrointestinal carbohydrate absorption at altitude $>5000 \mathrm{~m}$ has led to postprandial hypoglycemia, but later hyperglycemia, in which case, bolus insulin would be better taken with or even just after a meal, rather than the usual preprandial dosing (Admetlla et al., 2001). In addition, the tendency to favor a carbohydrate diet at altitude may require insulin dosage adjustment.

Dexamethasone raises insulin resistance even in nondiabetics (Zarkovic et al., 2008), so should be avoided for pro- phylaxis. The seriousness of HACE justifies emergency use, but will require frequent (hourly) BG monitoring. Both increases and decreases in BG have been reported with acetazolamide in rodents (Boquist et al., 1980a, 1980b; Sener et al., 2007; Pharmacy Retailing Limited, 2010), so if its use is contemplated for AMS prophylaxis, then trial before departure with appropriate insulin dose adjustment is advised. During the Diabetes Federation of Ireland Kilimanjaro Expedition 1999, the two sickest diabetics had been taking acetazolamide and one remained acidotic even after achieving euglycemia and resolution of ketonuria (Moore et al., 2001b). On this Kilimanjaro trip it is likely that overzealous insulin dose reduction, continued exertion while ketotic and dehydration were likely contributory factors since, in a later study on Kilimanjaro with a similar ascent profile, 8 of 11 type 1 diabetics took acetazolamide and they did not experience these problems (Kalson et al., 2007). Nevertheless, with the potential to worsen acidosis, some caution in the use of acetazolamide is advised.

Overall it would appear that insulin requirement is an integration of hypoglycemic factors (exercise, especially aerobic exercise, and reduced dietary intake) and hyperglycemic factors (short intense anaerobic exercise, stress, or AMS giving raised counter-regulatory hormones and the dawn phenomenon). Hence, an individual's dosing of long and rapid insulin requires a great deal of "trial and error" and acquisition of experience, and it is important that the diabetic is well practiced in their own particular dose adjusting requirements in environments and with the degree and duration of exercise, similar to those anticipated on the mountain (Panofsky, 2003).

\section{Insulin}

It follows that flexibility in insulin dosing is essential for optimizing control during exercise or altitude travel. Nondiabetics secrete low-level baseline insulin with bolus release to process carbohydrate meals (Galloway and Chance, 1994) (Fig. 1).

Fixed mixtures of short-acting (peak 1-2 hours, duration 6-8 hours) and intermediate (peak in 4-6 hours, duration 812 hours) insulins typically in a 30:70 or 50:50 ratio may limit the possibility of frequent adjustment and require a more regular routine (Fig. 2A). The most flexible dosing aims to mimic normal physiological response, hence the popularity of Basal-Bolus regimes (Gallen, 2005). This can be achieved by separate injections of intermediate acting baseline twice a day with short-acting boluses for meals (Fig. 2B). Newer insulin analogues such as Insulin Detemir, Insulin Glargine, or Insulin Degludec give a long-acting (16-24 hours) smooth, almost peakless, profile and can be given once a day, although some patients do find better control at twice daily (Fig. 2C) (Monthly Index of Medical Specialities [MIMS], 2013). Rapid-acting insulin analogues such as Insulin Aspart, Lispro, or Glulisine have onset in 10-20 minutes (peak in 1 hour, duration of 3-5 hours), facilitating dosing actually with, or just after, eating, thus removing the necessity to dose and plan eating 20-30 minutes ahead, which is often not possible in the mountains or when travelling, and on flights. The dose of mealtime rapid-acting insulin is calculated depending on the carbohydrate load and the degree, type, and duration of activity, with consideration of any remaining activity from previous insulin doses, and prevailing BG before eating. 


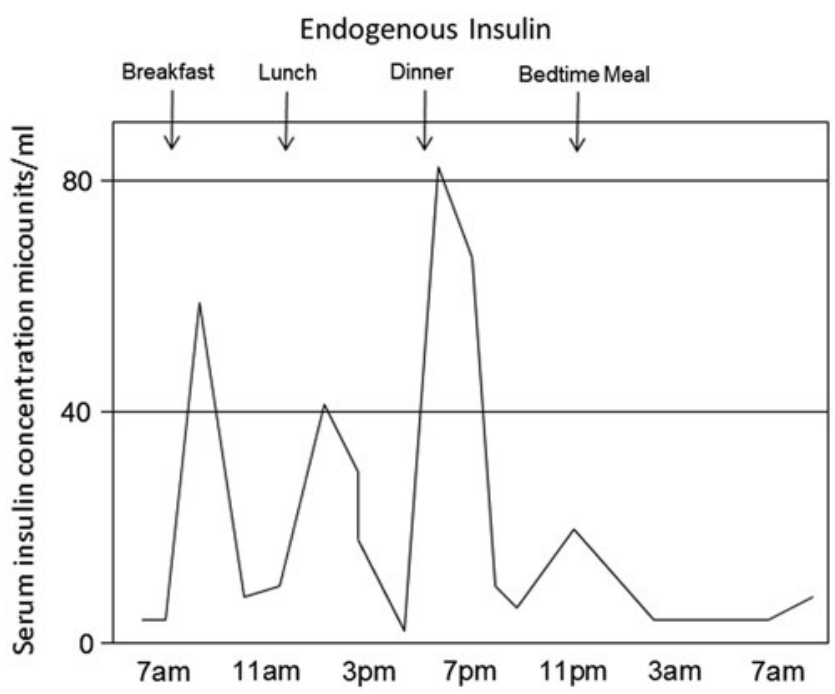

FIG. 1. Timing of insulin release in nondiabetics (adapted from Galloway and Chance, 1994).

Traditional insulin delivery systems of a bottle with separate needle and syringe have been superseded by convenient pen devices either as wholly disposable units or with replaceable disposable insulin cartridges. Unlike traditional syringes, the dose is determined simply by rotating a dial and pens can be obtained calibrated in half units for children or those on low doses. Some pens have accessories to ease use with arthritic hands, which are useful when wearing gloves. Pens and their cartridges may not be available in some countries, so travelling with adequate supplies is essential. In addition, U40 or U80 (cf U100 used in United States and Europe) concentration insulins are still available in some countries needing care if purchasing emergency supplies locally. Reassuringly, at least one tested pen device retained dose accuracy in simulated lifetime use under cold and heat stress (Xue and Mikkelsen, 2013).

Insulin pumps are gaining popularity, giving continuous low-dose infusion of subcutaneous rapidly acting insulin. These pumps afford the most precise microadjustment of dosing, but require training and familiarity. It is also important to carry a low technology backup such as insulin pens in case of pump failure (Mustafa et al., 2015). (For more detailed discussion on insulin pumps, see section Seven).

Diabetics usually rotate injection sites to prevent lipohypertrophy. Absorption is fastest from the abdomen, arm, and then thigh, although thigh absorption is increased during leg exercise due to enhanced subcutaneous blood flow (Koivisto and Felig, 1978).

Manufacturers specify that insulin must not freeze, be protected from light, and stored between $2^{\circ} \mathrm{C}$ and $8^{\circ} \mathrm{C}$, but advise viability at room temperatures $\left(<25^{\circ} \mathrm{C}\right)$ for up to a month after which they recommend it should be discarded (Personal Communication, Lantus storage requirements, K. Hiriyannaiah, Sanofi, January 30, 2013; Personal Communication, Travelling with insulin, Hema Customer Care and Information Line, Novo Nordisk, January 30, 2013; Personal Communication, R. Sayer, Wockhardt, February 1, 2013). Beyond 1 month, or at higher temperatures, degradation does not become harmful, but efficacy is not guaranteed and indeed higher temperatures such as $32^{\circ} \mathrm{C}-37^{\circ} \mathrm{C}$ for 28 days resulted in loss of potency of $14 \%-18 \%$ in one study ( $\mathrm{Vi}$ -
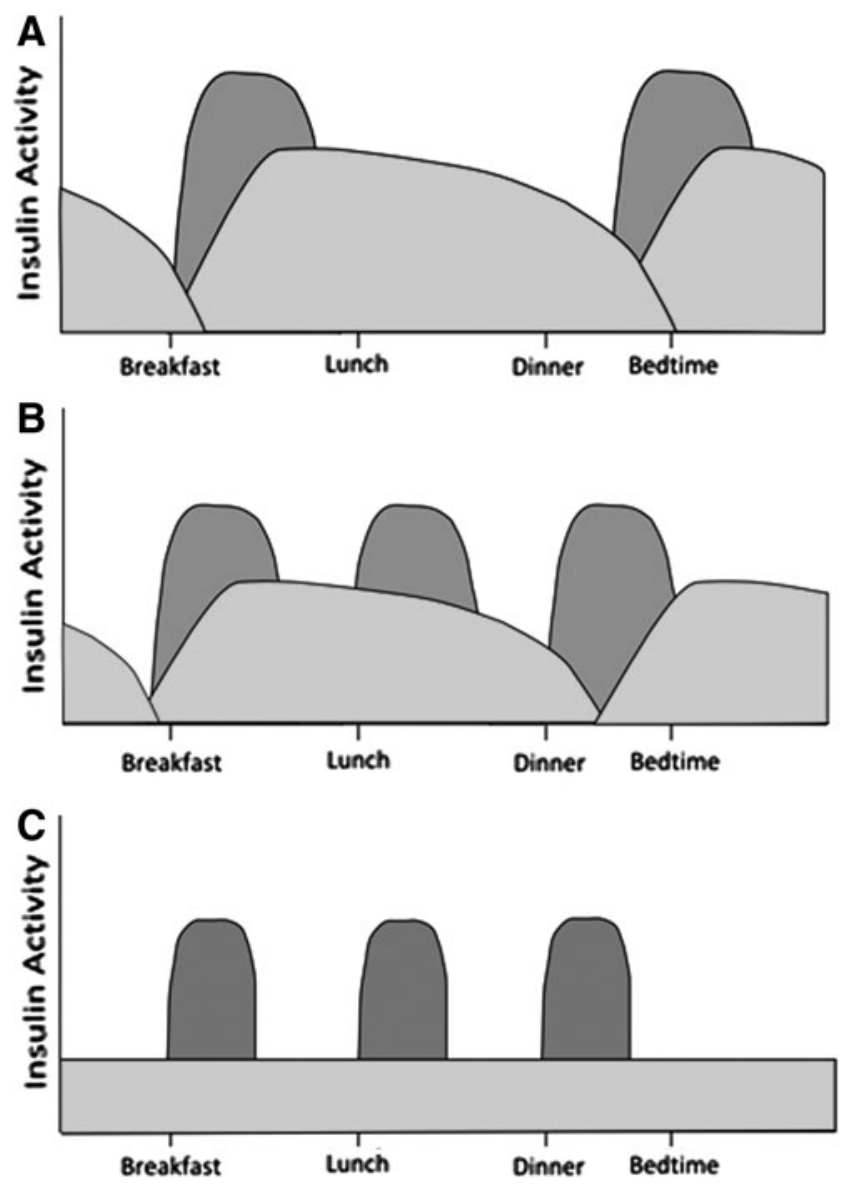

FIG. 2. (A) Twice-daily fixed short/intermediate insulin mix. (Rigid routine) Illustrative, after (MIMS, 2013). (B) Basal-bolus. Twice-daily intermediate- and short-acting bolus for meals. Illustrative, after (MIMS, 2013). (C) Basal-bolus. Long-acting peakless analogue insulin and rapid-acting bolus for meals. Illustrative, after (MIMS, 2013).

malavathini and Gitanjali, 2009). Viability of diluted Insulin Lispro at $30^{\circ} \mathrm{C}$ was, however, unchanged on day 32 (Stickelmeyer et al., 2000). Physical agitation of the molecule may possibly contribute to degradation. Doses may need increasing over time to compensate for reduced efficacy.

Needles should be removed from pens/vials after injection as air pressure or temperature changes can cause expulsion of fluid, potentially affecting homogeneity of the insulin.

\section{Glucometers}

It is important that the diabetic checks the end effect, that is, BG on a regular basis: before basal and meal dosing, and in between when exercising. This may result in testing 10 times a day, or more when exerting (Gallen, 2005). Several factors influence blood glucometer readings, including temperature, hematocrit, hypoxia, and site of sampling (Ginsberg, 2009). Modern meters operate typically between $10^{\circ} \mathrm{C}$ and $40^{\circ} \mathrm{C}$ and will alert or refuse to work outside these ranges. Low blood oxygen tension theoretically would cause glucose oxidasebased meters to overread, which was reported to be as much as $6 \%-15 \%$ in one study where glucose dehydrogenasebased strips were more accurate at altitude (Oberg and Ostenson, 2005), whereas other studies have shown the converse at moderate altitude (Olateju et al., 2012). Several studies 
confirm overreading or underreading at altitude of both reagents (Giordano et al., 1989; Gautier et al., 1996; Pecchio et al., 2000; Fink et al., 2001; Pavan et al., 2004; Bilen et al., 2007; Olateju et al., 2012) and discrepancy between simulated and real altitude (de Mol et al., 2010). Technological improvement may reduce these errors (Lock et al., 2011; Bailey et al., 2012), and in any case, the clinical effect would appear minimal unless overreading on the borders of hypoglycemia.

Meters are now available, which will also test blood ketones (using alternative specific testing strips), which is potentially useful in a wilderness environment by giving an earlier indication of potential ketoacidosis than traditional urinary test strips.

The TRUEresult meter is built into the lid of the testing strip canister and provides a small compact system that would be useful for a backup meter.

Blood sampling site is also important when low temperature reduces skin blood flow. This is more important at sites such as the forearm with prolonging of the usual 15-30 minutes lag time (Haupt, 2005). Fingertips are least affected due to arteriovenous shunting.

CGMs are useful for showing trends, but as they measure from interstitial fluid and not capillary blood, they have a prolonged lag time, which may cause difficulty with insulin dosing. Integrated systems linking CGM with insulin pumps through a computer algorithm offer the exciting prospect of "artificial pancreas" (Peyser et al., 2014). Their usefulness in intense exercise or at altitude remains to be demonstrated. More detailed information is available in section Seven.

Most meters are now amperometric, measuring current as electrons are released by chemical interaction with glucose, and there are few photometric meters now available (e.g., Accucheck Active), where glucose measurement is indicated by change of reagent strip color. The latter is useful for manual reading backup in case of meter failure, but is not reliable in the orange tinge or other colored light inside a tent! Test strips can be damaged by high temperatures or humidity and must be stored with desiccant in sealed containers.

\section{Hypoglycemia}

The major concern of many diabetics is hypoglycemia, particularly in safety critical situations, and many diabetics choose to run their BG slightly high $(7-9 \mathrm{mmol} / \mathrm{L}, 126-$ $160 \mathrm{mg} / \mathrm{dL}$ ) when away, to minimize this risk. Hypoglycemia symptoms show interindividual variability, but are usually consistent within an individual and may manifest as fatigue, hunger, agitation, trembling, difficulty with fine motor tasks (buttons, ropes, and belay devices), sweating, palpitations, aggression or behavioral change, or, if particularly severe, reduced Glasgow Coma Scale (GCS), coma, or seizures. BG below $4 \mathrm{mmol} / \mathrm{L}$ or $72 \mathrm{mg} / \mathrm{dL}$ requires prompt treatment with fast-acting carbohydrate, to which the diabetic should always have ready access, for example, snack bars or glucose sweets/ drinks. Glucose gels (Glucogel) can be applied to the buccal membrane by companions or Glucagon $1 \mathrm{mg}$ s.c./i.v./i.m. injected. Absorption of the latter will be impaired by cool muscles and will be ineffective if the hypoglycemic episode has been caused by depletion of glycogen stores, which is quite possible at the end of a long mountain day. Hypoglycemia can lead to hypothermia and both can be confused with AMS (Moore et al., 2001a). Any unwell diabetic should have prompt and repeated BG measurements. After treatment of a significant "hypo," a diabetic can feel fatigued with clouded judgment for up to 2 hours.

Hypoglycemic awareness, where the diabetic is able to recognize symptoms associated with hypoglycemia in sufficient time to take remedial action, can be impaired with frequent hypoglycemia resulting in a six-time increase in the risk of severe (i.e., requiring the assistance of a another person) hypoglycemia (Geddes et al., 2008). Awareness can be regained after 3 to 4 weeks of good diabetic control with an absence of hypoglycemic episodes (Cranston et al., 1994; Dagogo-Jack et al., 1994; Bakatselos, 2011).

Hypoglycemia can occur hours after the intense physical activity required for mountaineering/rock climbing/ice climbing. For example, a person may be able to successfully prevent hypoglycemia, while climbing by checking and consuming carbohydrates frequently, but may develop hypoglycemia later, after having had a hearty meal. It is recommended that glucose be checked at bedtime and in the middle of night (2-3 am). If hypoglycemia is anticipated, the threshold for bedtime snack should be increased from the usual number (often less than $5.5 \mathrm{mmol} / \mathrm{L}, 100 \mathrm{mg} / \mathrm{dL}$ ) to less than $7.8 \mathrm{mmol} / \mathrm{L}, 140 \mathrm{mg} / \mathrm{dL}$.

People with "brittle" type 1 diabetes with severe insulin deficiency (almost absolute insulinopenia) should consider limiting their activities to areas with good communications in terms of both advice and transport.

\section{Hyperglycemia and ketoacidosis}

General advice in the wilderness to monitor hydration by observing urine color is complicated in diabetics by an osmotic diuresis once $B G$ exceeds $10 \mathrm{mmol} / \mathrm{L}$ or $180 \mathrm{mg} / \mathrm{dL}$. Thus, the relatively clear urine may give false reassurance, when in fact the hyperglycemic diabetic is dehydrating. In a wilderness setting, ketoacidosis carries a high risk of mortality (Shlim and Gallie, 1992; Basnyat, 1995). It would appear that it is a relative lack of insulin (reduced or no dosing, reduced efficacy from environmental/heat damage, and incorrect dosing due to meter error) in conjunction with other factors such as dehydration, infection, AMS, or continuing to exercise with ketonuria that particularly raises risk (Moore et al., 2001b; Leal, 2005). Carriage of a glucometer, which can also read blood ketones, with appropriate test strips would be advised.

\section{Practicalities}

For customs, carriage of medication in original packaging is advised, along with a letter from the prescribing physician. Airport security X-ray machines are not considered harmful to insulin itself, but these or airport body scanners might damage insulin pumps or CGMs, which should be removed and checked manually (Cornish and Chase, 2012). Security now commonly requires separate manual presentation of liquids to staff for examination. Taking twice the estimated maximum required amount of insulin, needles, test strips, lancets, and other consumables for the trip along with spare glucometers and batteries would be recommended. Drugs and equipment should be carried in hand luggage to prevent freezing in baggage holds and, at destination, split between team members in case of individual bag loss. Pump users should carry spares, and for all, a low-tech option, such as traditional insulin needles and syringes in case of failure of the primary system and the need to obtain local insulin supplies. The availability of the latter and location of local health 
clinics are best determined before departure; The International Society of Travel Medicine (International Society of Travel Medicine, 2013) provides a register for worldwide clinics, which can give a starting point for researching local facilities. If possible, some insulin should be stored in a reliable refrigerator at the arrival city, so that at the end of the expedition, the diabetic can return to fully efficacious insulin.

In cold environments, many diabetics utilize body warmth to prevent insulin, meters, and batteries freezing by storing in pouches, sometimes commercially available like old transceiver bags or otherwise homemade from fleece or other insulating material, worn outside their base layer thermal underclothes, similarly taking kit inside sleeping bags at night. Such holders and use of tape and tethering cord also reduce risk of dropping kit when on climbs. Others carry their insulin wrapped in bubble wrap inside food-/drink-type vacuum flasks or create homemade closed-cell foam pouches heated by disposable chemical heat pads. In hot conditions, water-evaporative cooling from proprietary pouches such as Frio ${ }^{\circledR}$ or Poucho ${ }^{\circledR}$ palpably reduces insulin temperature by a few degrees.

BG testing can be difficult in a storm, and wet or windy conditions tend to be more problematic than snow. Some diabetics will cut the tips off inner gloves to give a testing flap. Thigh ventilation zips enable access for injections and some manufacturers will adapt clothing with extra zips/Velcro $^{\circledR}$ to assist access at other sites. In really bad weather conditions, a bothy bag provides warmth and wind protection. Equipment such as climbing harnesses may prevent access to usual injections sites and alternatives should be practiced before departure. Disposable insulin needles are designed for single use and quickly become jagged if reused. Direct injection through clothing, although practiced by some, risks introducing infection or fiber fragments into the skin, predegrades sharpness of needles before skin contact, and is likely to require longer needles to ensure adequate penetration.

Small sharps boxes (e.g., 0.3-0.5 L) are available for safe carriage of used needles, lancets, and test strips during the trip. Safe disposal may follow local guidelines where they exist, but in some developing economies, it may be more appropriate to at least repatriate the sharps and dispose them once home. In this case, a needle cutter (e.g., BD Safe-Clip ${ }^{\circledR}$ ) drastically reduces sharp waste volume.

It is vital to inform companions of the diabetes, not least as any illness is likely to impact their trip, maybe even placing them into danger. It is also sensible to educate them in hypoglycemia recognition and treatment, including where glucagon is kept, and, when and how to inject it if needed. Ideally, the diabetic should be accompanied by someone who knows them well and who can detect subtle signs of hypoglycemia, prompting glucose testing. It is wise for all to share accommodation at high altitude, so that severe illness might be detected, but particularly so for diabetics. Insurance, which includes medical cover, search, and rescue and repatriation by air ambulance, is advised, and best sought in good time as it may require a specialist provider.

\section{Summary}

- Ensure travel with adequate testing and insulin supplies with $100 \%$ spares in case of loss or delays. Carry in hand luggage as aircraft holds may have a freezing risk.

- East to West Travel: day prolonged-additional carbohydrate meal and insulin bolus.
West to East Travel: day shortened-reduce total insulin dose.

- Hyperglycemic factors: underdosing insulin, stress, intercurrent illness, short intense bursts of exercise, and AMS.

- Hypoglycemic factors: Insulin, sustained steady exercise, and reduced food intake.

- Possible delayed gastrointestinal carbohydrate absorption at altitude predisposes to postprandial hypoglycemia-take insulin with or just after meals.

- Overall, diet and exercise probably have a greater influence on glycemia than altitude.

- Hypoglycemia in a wilderness environment can be particularly dangerous, so many diabetics choose to maintain their sugars slightly raised, but controlled. Companions should be aware of presenting signs and symptoms and remedial action (Oral glucose and i.m. glucagon).

- Insulin Basal-Bolus regimes afford greatest flexibility in matching insulin to diet and activity.

- It is essential for the diabetic to be familiar with managing diabetes and insulin dose adjustment in the environment, and with the degree and duration of exercise anticipated at altitude. Trial runs at lower altitude can assist in gaining experience.

- Insulin must not freeze, but will remain viable at "room temperature" for a month with loss of efficacy in higher temperatures or after this date. Storage in insulated containers or use of proprietary evaporative cooling bags can assist in maintaining a temperature near optimal.

- Glucometers may underread or overread at high altitude, but the clinical significance is probably minimal.

- With frequent capillary blood sugar testing and a basalbolus regime, many conflicting theoretical considerations can be minimized as it is all dealt with on a practical level.

\section{Section Six: Oral Hypoglycemic Medication for Mountaineers with Diabetes and Their Medical Advisors}

\section{Hypoglycemic medication can interact with altitude physiology}

Table 1 describes the main classes of oral hypoglycemic medication, their mechanism of action, and the main side effects.

Biguanides may cause lactic acidosis. Although the incidence of metformin-associated lactic acidosis (MALA) is generally extremely low (Salpeter et al., 2010), MALA is a serious complication with a mortality rate ranging from $10 \%$ to $40 \%$ (Visconti et al., 2016). The risk is increased in patients with reduced metformin or lactate clearance (impaired kidney and liver function) by hypoxemia and dehydration (Visconti et al., 2016), and especially in patients with an estimated Glomerular Filtration Rate less than $30 \mathrm{~mL} / \mathrm{min} /$ $1.73 \mathrm{~m}^{2}$ (Lazarus et al., 2018). Nevertheless, in healthy active men exercising at sea level, metformin increased oxygen consumption and actually lowered lactate levels (Johnson et al., 2008), possibly due to changes in carbohydrate utilization. These data raised the hypothesis that metformin could increase exercise performance in hypoxic conditions. In healthy young men in acute normobaric hypoxia $\left(\mathrm{F}_{\mathrm{IO} 2}=\right.$ 0.15 ), short-term metformin administration (1000 mg daily for 3 days) decreased insulin clearance in response to a highcarbohydrate meal, and promoted skeletal muscle glycogen 
Table 1. Main Classes of Oral Hypoglycemic Medication, Their Mechanisms of Action, and the Main Side EfFects

\begin{tabular}{|c|c|c|c|}
\hline Class & Example & Mechanism & Side effects \\
\hline Biguanides & Metformin & $\begin{array}{l}\downarrow \text { Hepatic glucose production } \\
\uparrow \text { Peripheral insulin sensitivity }\end{array}$ & $\begin{array}{l}\text { Hypoglycemia } \\
\text { Lactic acidosis } \\
\text { GI symptoms }\end{array}$ \\
\hline $\begin{array}{r}\text { Sulfonylurea } \\
\text { derivatives }\end{array}$ & Tolbutamide & $\uparrow$ Insulin release by depolarizing pancreatic $\beta$-cell & Hypoglycemia \\
\hline $\begin{array}{l}\text { GLP1 agonists } \\
\text { DPP4 inhibitors }\end{array}$ & $\begin{array}{l}\text { Liraglutide, } \\
\text { Linagliptin }\end{array}$ & $\begin{array}{l}\uparrow \text { Insulin release by depolarizing pancreatic } \beta \text {-cell } \\
\downarrow \text { Hepatic glucose release by } \downarrow \text { glucagon } \\
\quad \text { delay gastric emptying }\end{array}$ & $\begin{array}{l}\text { Hypoglycemia (if combined } \\
\text { with insulin or sulfonylurea) } \\
\text { GI symptoms } \\
\text { Upper RTI }\end{array}$ \\
\hline SGLT2 inhibitors & Dapagliflozin & $\downarrow$ Glucose resorption in renal tubule & $\begin{array}{l}\text { Diabetic Ketoacidosis } \\
\text { Dehydration } \\
\text { Hypoglycemia (if combined } \\
\quad \text { with insulin or sulfonylurea) }\end{array}$ \\
\hline Thiazolidinedione & Pioglitazone & $\uparrow$ Peripheral insulin sensitivity (via PPAR $\gamma$ ) & $\begin{array}{l}\text { Hypoglycemia (if combined } \\
\text { with insulin or sulfonylurea) } \\
\text { Fluid retention }\end{array}$ \\
\hline Others & Acarbose & $\begin{array}{l}\downarrow \text { Glucose absorption in small intestine } \\
\quad(\downarrow \text { Conversion of polysaccharides } \\
\text { into monosaccharides) }\end{array}$ & $\begin{array}{l}\text { Treatment of any hypoglycemia } \\
\text { requires glucose and not other } \\
\text { sugars or carbohydrates }\end{array}$ \\
\hline
\end{tabular}

DPP4, dipeptidyl peptidase-4; GI, gastrointestinal; GLP1, glucagon-like peptide-1; PPAR $\gamma$, peroxisome proliferator-activated receptor gamma; RTI, respiratory tract infection; SGLT2, sodium/glucose cotransporter2.

synthesis, but did not influence endurance exercise performance (Scalzo et al., 2017). In addition, one study describes eight trekkers using metformin on a trekking trip to $4167 \mathrm{~m}$ without any adverse effects (de Mol et al., 2012).

Data on the use of sulfonylurea derivatives at high altitude are scarce. One small study describes their use in three participants on a 12-day trek to $4167 \mathrm{~m}$ without any adverse effects (de Mol et al., 2012). They do, however, advise considering a reduced dose of sulfonylurea derivatives during prolonged submaximal exercise (de Mol et al., 2014). Of note, in several cases, the oral hypoglycemic agent acetohexamide was mistaken for acetazolamide (Hargett et al., 1977; Raab, 1979; Olson et al., 1991; Rutzen and Weiss, 1993; Litch, 1996; Sabb and Allen, 1999).

Thiazolidinediones (TZD) are associated with plasma volume expansion. In vitro studies describe TZD stimulating the renal sodium coupled bicarbonate transporter in the proximal tubule (Endo et al., 2011). Acetazolamide blocks this transporter, and thus abolishes these volume expansion effects in rats (Endo et al., 2011). No literature describes the use of TZDs at high altitude.

One case report describes the use of DPP4 inhibitors on a trekking trip to $4167 \mathrm{~m}$ without any adverse effects (de Mol et al., 2012).

Based on these limited data and expert opinion, it is recommended that diabetics using oral hypoglycemic drugs continue their use at altitude, but consider reducing the dosage of insulin and/or sulfonylureas during prolonged exercise. Diabetics should consider carrying short-acting insulin to correct hyperglycemia shortly after arriving at higher altitudes, but only if they have the knowledge and skills to do this. When using metformin, avoid hypoxemia and dehydration, and consider lowering the metformin dose to reduce the already low risk of MALA. When using SGLT2 inhibitors, we recommend careful attention to fluid replacement to avoid dehydration.

\section{Medication that is used for prevention and treatment of altitude sickness interacts with glucose regulation}

Acetazolamide has been reported to either increase (Miller, 2015) or not clearly influence (de Mol et al., 2011) insulin requirements in type 1 diabetic patients. Acetazolamide stimulates renal bicarbonate excretion, and thus has been suggested to enhance ketoacidosis in diabetic patients (Moore et al., 2001b), especially in patients with compromised kidney function (Swenson, 2014). However, in the study by Moore et al., insulin doses were reduced drastically. Reduced insulin doses combined with dehydration and continued exertion may have contributed to increased development of ketoacidosis. Other studies, using more gradual ascent profiles, do not describe increased rates of hyperglycemic ketoacidosis (Kalson et al., 2007; de Mol et al., 2011). Under controlled laboratory conditions, acetazolamide was used in combination with a hyperinsulinemic clamp to study cerebral blood flow in hypoglycemia. Participants who received acetazolamide $(1 \mathrm{~g}$, i.v.) were less aware of hypoglycemia and had fewer adrenergic symptoms (sweating, palpitations, and tremors) and lower plasma epinephrine levels compared to placebo controls (Thomas et al., 1997). How these hyperinsulinemic clamp studies, using high doses of acetazolamide, translate to the outdoors is unknown; however, the consequences of unnoticed hypoglycemia should be kept in mind.

Of interest, one study describes improved HbA1c in type 2 diabetics using methazolamide, a carbonic anhydrase inhibitor, for 24 weeks (Simpson et al., 2014). Methazolamide may be equally effective in preventing and treating AMS compared to acetazolamide (Wright, 1994; Hun Lee and Choi, 2011). Methazolamide could therefore be of interest in the prevention or treatment of AMS in diabetic mountaineers. However, currently the effect of short term use of methazolamide on glucose regulation is unknown, and only a couple 
of studies describe its use in treatment of AMS. Therefore at this moment, we do not recommend use of methazolamide for prevention or treatment of AMS in diabetics.

Based on these data, it is not recommended to use acetazolamide for primary prevention of AMS in diabetic patients. Gradual ascent provides a much safer alternative (Admetlla et al., 2001). Furthermore, diabetics who do contemplate use of acetazolamide should trial with appropriate insulin dose adjustment before departure, and monitor their glucose levels regularly to avoid hyperglycemia.

Dexamethasone induces peripheral insulin resistance and increases plasma glucose concentration. In addition, it can potentially increase kaliuresis, aggravating the potassium depletion during diabetic ketoacidosis (Miller, 2015). When used as postoperative nausea and vomiting prophylaxis $(8 \mathrm{mg}$ i.v.), type 2 diabetic patients had a similar increase in glucose concentrations compared to controls (Nazar et al., 2011). No literature describes the use of dexamethasone in diabetics at altitude.

Based on expert opinion, it is not recommended to use dexamethasone for primary prevention of AMS in diabetics. However, it is recommended to use dexamethasone to treat HACE; glucose levels should be regularly monitored to avoid severe hyperglycemia.

Nifedipine may increase plasma concentrations of metformin as demonstrated in rats, hence increasing the risk of lactic acidosis (Choi and Lee, 2012). No literature describes the use of nifedipine in diabetics at altitude.

Based on expert opinion, it is recommended to use nifedipine to treat HAPE in diabetics.

\section{Section Seven: Recent Technology Developments in Diabetes Care}

In addition to insulin regimes of multiple daily injections (MDIs, using basal and bolus insulins), diabetics are using increasingly sophisticated methods to manage their diabetes in the mountains as in their daily lives.

Technological advances, increasing reliability and increased affordability of computerized syringes known as "insulin pumps," CGM, and newer smart intelligent systems, have enabled individuals to take their diabetes management and control to a new level and are considered by some clinics as "the gold standard" in terms of an athlete's diabetes management.

Using this flexible technology to micromanage diabetes in the mountains, at high altitude, or on remote area expeditions not only brings advantages but also additional challenges that must be carefully considered by the diabetic mountaineer, trip medic, and leader. High altitude, mountain environments, or pressure changes when flying can have a significant effect on BG levels and perceptions of hypoglycemia, and adventure travel will undoubtedly result in irregular mealtimes, different foods, and effects of altitude on digestion, in addition to the increased basal insulin requirements at altitude.

The main advantages of using an insulin pump lie in the ease of administering boluses, modifying the administration time, rate and duration of bolus delivery, and changing basal rates. Insulin can even be stopped for a short time if required.

Being able to give an insulin bolus without having to physically access injection sites has significant advantages in the mountains where multiple layers of clothing, outer shell layers, climbing equipment, harnesses, and sleeping bags can all hinder access and may even delay the administration of an injection due to the practical difficulties involved in adverse weather.

Above $5000 \mathrm{~m}$ the rate of digestion may differ from that at sea level. The ability to administer insulin with a delayed start time, over an extended period of time, or as a multiwave regime, where the bolus is split into that required straight away and then the remainder delivered over an extended period, can mean that the risk of postprandial "hypos" is be minimized.

Being able to adjust a basal rate according to athletic and metabolic requirements is also a key advantage of using insulin pumps. An unanticipated, but sustained need for aerobic activity may precipitate an individual into hypoglycemia if no changes are made either to insulin being delivered or carbohydrates being ingested. Numerous studies have shown that being at high altitude can require an increased basal background rate of insulin (Admetlla et al., 2001; Pavan et al., 2003; Brubaker, 2005; Leal, 2005; de Mol et al., 2011).

For diabetics' successful mountain climbing, remote area travel, and being at altitude require an awareness of possible environmental and physiological variables likely to be encountered, plus an ability to be able to respond to subsequent $\mathrm{BG}$ readings by changing insulin dosages. For those using modern diabetic control systems, an additional competence in troubleshooting technological issues plus the practical implications that will be encountered is essential. It would be like using a global positioning system without knowing how the unit works or having the backup of a map and compass!

Ongoing glucometer development is regularly adding additional functions such as more sophisticated data storage and presentation, advisory guidance on insulin dosing according to preset $\mathrm{BG} /$ personal insulin dose requirement ratios, and wireless communication to smartphone apps.

Modern medical technology requires battery power. The more complex the monitoring or the delivery system the more power that is used. Multicolored LCD screen displays and Bluetooth communication between pumps, CGMs, glucometers and display handsets increase power requirements. which can impose limitations on long-duration expeditions or necessitate complex charging systems which can, in turn, be temperature sensitive and fail. In cold conditions some diabetic technology may simply cease to function. Some handset units are now only being manufactured with mains USB chargers, which could pose a problem if without mains electricity for a period of time. Wearing sunglasses or the bright sunlight and glare in the mountains can make insulin pump and CGMs with full color display screens impossible to read.

The cheapest and most reliable method to ensure that pumps and meters function is to use a pouch that can be used to hold the items close to the user's body for extra warmth. If this is done, be aware of excessive sweat potentially affecting the units and of humidity affecting testing strips. Other alternatives are to use air-activated warmers, which use ambient oxygen to create an exothermic chemical reaction. These can be placed near any unit, but beware of overheating, which may adversely affect any LCD screen and operating parameter of BG meters and strips.

Insulin pumps and related diabetes devices are typically tested by their manufacturers in hypobaric chambers at altitudes between 3000 and $4800 \mathrm{~m}$, and research by diabetic mountaineers expeditions have reported successful CGM use on Kilimanjaro 5895 m (de Mol et al., 2011). Insulin pumps have been successfully used on many high-altitude expedi- 
tions, including summits such as Aconcagua, $6960 \mathrm{~m}$. Due to barometric pressure change with altitude, it is essential to regularly check and prime out any air bubble in both insulin pump cartridges and infusion tubing on ascent and with pressure changes of air travel. Both air coming out of solution and preexisting bubbles in the insulin cartridge or line will expand and can cause an unintended insulin delivery (King et al., 2011). Panofsky (2003), expedition leader for the first diabetic expedition to Aconcagua $6960 \mathrm{~m}$ in 2000, recommends having a personal system of checking and purging equipment for every $1000 \mathrm{~m}$ of ascent or descent.

When planning an expedition using insulin pumps, CGMs, and associated devices, it is essential to consider the practicalities well in advance and have regularly trialed the devices to ensure full knowledge of any complication that may occur in the worst weather conditions in difficult terrain. Familiarity is essential so avoid any last-minute changes in a personal system just before departure.

When mountaineering with diabetes-related technology, one of the main considerations is where and how the technology should be worn for comfort, function, and ease of access. Considerate positioning of the insulin pump cannula or CGM sensor for the type and duration of mountain sport is crucial to minimize chaffing, dislodging, and bruising from unanticipated pressure points. Some users have commented on inserting a spare cannula ready, in case a problem is encountered with the original cannula being used. If the user finds that the cannula adhesive repeatedly displaces due to sweat, then specific sprays such as Cavillon ${ }^{\circledR}$ or even cheap antiperspirant deodorants can enable the plaster to stick to the skin for longer periods. Kinesiology tape, also known as Rock Tape, as used by physiotherapists for sport strapping, can also be useful when sweat proves to be a problem.

The diabetic mountaineer has to continually plan ahead knowing when insulin is likely to run out and when cannulas will need to be changed. Alarms and infusion set changes can be very inconvenient if they involve leaving a snug sleeping bag at $2 \mathrm{am}$ and waking your tired climbing partner in the process. Some cartridges for insulin pumps are designed to be hand loaded and with careful planning, can take sufficient insulin for 2 to 3 days, so can be used to cover multiday routes or to ensure cartridge changes are likely to be undertaken when in the shelter of a camp.

Different individuals have different preferences in how and where to wear their insulin pumps and related handsets/ glucometers. Some make their own cases out of fleece or neoprene, which are carried around their neck, enabling ease of access to both pump and glucose meter, with minimal interference from climbing harnesses and rucksack straps, and giving protection from cold environments. There are so many different commercially available devices and cases on the market ranging from belt clips, harnesses, waist pouches, bra pouches, and thigh/leg pouches that it is impossible to review and recommend a specific one.

The effect of the cold and even extreme sunlight on both insulin and BG test strips and glucometers has been covered in section Five and the same principles of avoiding these extremes apply to insulin pump and CGM-related technology as battery-operated devices tend not to function well at extremes of temperature. Excessive heat can render some screens unreadable for long periods or even indefinitely. On trips away from refrigerators, Frio wallets (section Five) can be used for many items.
Insulin pumps and CGMs are becoming increasingly affordable and reliable, although unlike the simplest system of diabetes management (syringes/pens and insulin and BG test strips with no meter), contingency planning must cover device failure. This involves the ability to revert back to MDIs, and should include carrying a background basal insulin with a preprepared conversion chart of the approximate total daily dose of the rapid-acting insulin analogue normally used as basal by the pump. This is also useful, should the individual need to convey insulin needs to local medical practitioners. U-100 syringes are typically orange in color, but U-40 syringes are red in color.

Advance consideration of all the supplies and spares that will be needed for the duration of the expedition is essential. Calculate the amount and then double it in case of loss or theft: spare batteries, spare insulin cartridges (prefilled or empty), spare insulin, spare infusion tubing, and spare cannulas and backup inserter devices if used. In mountaineering, there is always a balance between carrying just enough equipment, so that you do not get benighted and not carrying so much that it becomes inevitable. Prior planning of standard supplies and spares is essential and with modern technology, this becomes even more important. Remember that reaching the summit is only half the journey. Sometimes, no matter how many relevant spares are carried, an awareness of the quickest way off the mountain will be the safest decision for all.

Continuous subcutaneous glucose monitoring consists of a sensor that sits under the skin, which monitors interstitial fluid glucose levels and either relays automatically to a receiver device unit, which displays the continuous glucose readings (such as with the Dexcom G4 CGM, Dexcom Seven+ CGM; Medtronic Paradigm REAL-Time CGM; Medtronic Guardian REAL-Time CGM), or the Abbott Freestyle Libre, which is manually scanned by the user over the sensor to obtain the past 8-hour readings. Informal evidence from the media and Mountains for Active Diabetics (MAD) user group suggests that there is no difficulty in obtaining readings, regardless of clothing layers that are worn. Some CGM systems (like the Dexcom G4 platinum CGM used with the Animas Vibe insulin pump) communicate directly with each other, allowing both continuous glucose readings to be displayed on the same pump screen that is delivering the insulin, alleviating the need for a separate unit. The sensors themselves need to be changed every 3-14 days depending on the make, and the sensor transmitter device batteries typically can last up to 6 months before needing either changing or recharging. Newer technologies are constantly being developed and at the time of writing, MiniMed has released the first "intelligent" pump (MiniMed 640G insulin pump with SmartGuard CGM), which predicts low blood sugars and automatically stops insulin delivery, then resuming insulin delivery once glucose levels have recovered. It will be interesting to see how these are used in the mountains.

Some CGM devices need to be calibrated with BG readings at least every 12 hours and it takes a new sensor $\sim 2$ hours to be ready for use after insertion; the need for BG monitoring is not completely eliminated. The CGM systems that do not require calibration should still be checked for reliability using a meter. There is also a "lag" time between interstitial and capillary $\mathrm{BG}$ readings, meaning that the $\mathrm{BG}$ could be much lower than that displayed on the screen, and most manufacturers and users recommend reverting to BG testing if hypoglycemic symp- 
toms are experienced or if the pump or CGM screen displays a rapidly decreasing glucose profile.

The minimal-impact philosophy of pack it in, pack it out, has never been as relevant as to those who are travelling and staying in the mountains with diabetes. Each cannula, infusion line, sensor, glucose strip, and so on comes packed in protective packaging, keeping them sterile and in an appropriate dry environment ready for use. The advantage of taking along supplies in their original packaging is that the items should maintain their sterility, if not damaged. This has to be balanced against bulk and the necessity to carry all the packaging out again. Many individuals take their pump and CGM supplies out of their original packaging before trips and simply pack them in suitably protective cases such as Peli ${ }^{\mathrm{TM}}$ cases, thereby reducing expedition waste and luggage bulk. Most manufacturers' guidelines recommend changing the cannula every 2-3 days and changing the infusion line every 6 days. This does not take into account the need to change both cannula and infusion line if there is a problem with insulin delivery such as an occlusion or unexplained hyperglycemia. When travelling, it is sensible to keep supplies with you at all times, especially when flying.

Most western airport staff training covers individuals wearing medical devices and insulin pumps. Most insulin pump manufacturers recommend that their devices are not put through X-Ray machines, and especially not the newer whole body scanners. It is recommended to contact the manufacturer of each device or visit their website for advice regarding travel using their devices. In addition, even if frequencies of communication between the pump and glucometer, or sensor and CGM monitor, are compatible with inflight specifications, it is also recommended that devices are put into "manual" or "flight mode," especially during take-off and landing or if requested by airline staff. If there is a concern from airport security staff regarding the insulin pump being retained on the person, then individuals should request a "walk through" or hand/wand inspection. New aviation regulations also require that all lithium batteries are carried in hand luggage.

Some of this information may appear daunting and it is important that a mountaineering diabetic is confident with whatever system they choose to use, be it high or low tech. Any system must have a backup. As with any mountaineering, skill practice is the key to safe and confident management.

\section{Further Information}

Mountains for Active Diabetics. www.facebook.com/ groups/131297830871/

An international group of mostly lay diabetic mountaineers and active outdoor enthusiasts with a wealth of practical experience in managing diabetes in extreme conditions.

Useful advice on insulin dose adjustment when crossing time zones: http://diabetestravel.org

Think Like a Pancreas 2nd Edition. Gary Scheiner. Pub: Da Capo Lifelong Books; November 2011.

ISBN-10: 0738215147; ISBN-13: 978-0738215143

Diabetic Athlete's Handbook 1st Edition. Sheri R. Colberg. Pub: Human Kinetics Europe Ltd; January 2009

ISBN-10: 0736074937; ISBN-13: 978-0736074933

Type 1 Diabetes: Clinical Management of the Athlete. Gallen I. Pub: Springer; March 2012

ISBN-10: 0857297538; ISBN-13: 978-0857297532

\section{Acknowledgments}

We would like to thank Dr. Enrico Donegani (UIAA Medcom) for referencing, Dr. Marieke van Vessem (UIAA Medcom) for proof reading, and Ms. Nicola Simpson, nonmedical diabetic mountaineer, for lay review and opinion.

\section{Consensus}

At the UIAA Medcom meeting in 2008 in the Czech Republic, it was agreed to update the advice article for mountaineers with specific preexisting medical conditions (Consensus Article No. 13) with specific articles for different conditions. The work on this article was started in 2015 after the meeting in Greece and the first major draft was reviewed at the Kathmandu meeting in 2017. Further sections were added and the drafts then circulated to all Medcom members from January, 2018, for final approval in March, 2018. Revision in view of peer review comments was finalized in July, 2018.

\section{Author Disclosure Statement}

Three of the authors, P.R., N.W., and D.H. are insulindependent mountaineering diabetics and inevitably use some of the products mentioned in the text.

\section{References}

Admetlla J, Leal C, and Ricart A. (2001). Management of diabetes at high altitude. Br J Sports Med 35:282-283.

Admetlla J, Leal C, and Ricart A. (2003). Diabetes mellitus and mountain sports. In: Health \& Height. Proceedings of the 5th World Congress on Mountain Medicine and High Altitude Physiology. G Viscor, A Ricart, and C Leal, eds. Universitat de Barcelona Publicacions, Barcelona, Spain.

Ahlborg G, Wahren J, and Felig P. (1986). Splanchnic and peripheral glucose and lactate metabolism during and after prolonged arm exercise. J Clin Invest 77:690-699.

American Diabetes Association. (2015). Diabetes Statistics. Available at http://www.diabetes.org/diabetes-basics/statistics/ (accessed October 5, 2018).

Bailey T, Chang A, Rosenblit PD, Jones L, Teft G, Setford S, and Mahoney JA. (2012). A comprehensive evaluation of the performance of the test strip technology for OneTouch Verio glucose meter systems. Diabetes Technol Ther 14:701-709.

Bakatselos SO. (2011). Hypoglycemia unawareness. Diabetes Res Clin Pract 93 (Suppl 1):S92-S96.

Bartsch P, and Gibbs JS. (2007). Effect of altitude on the heart and the lungs. Circulation 16:2191-2202.

Basnyat B. (1995). Himalayan Rescue Association. Diabetic ketoacidosis in mountain trekkers. ISMM Newsletter 5:4-5.

Bilen H, Kilicaslan A, Akcay G, and Albayrak F. (2007). Performance of glucose dehydrogenase (GDH) based and glucose oxidase (GOX) based blood glucose meter systems at moderately high altitude. J Med Eng Technol 31:152-156.

Boquist L, Backman AM, Stromberg C. (1980a). Effects of acetazolamide on insulin release, serum glucose and insulin, glucose tolerance, and alloxan sensitivity of mice. Med Biol 58:169-173.

Boquist L, Backman AM, and Stromberg C. (1980b). Hyperglycemia produced in mice by administration of acetazolamide and diphenylhydantoin. Eur J Pharmacol 64:325-332.

Brubaker PL. (2005). Adventure travel and type 1 diabetes: The complicating effects of high altitude. Diabetes Care 28:25632572 . 
Buda R, Di Caprio F, Bedetti L, Mosca M, and Giannini S. (2013). Foot overuse diseases in rock climbing: An epidemiologic study. J Am Podiatr Med Assoc 103:113-120.

Burtscher M. (2007). Risk of cardiovascular events during mountain activities. Adv Exp Med Biol 618:1-11.

Chandran M, and Edelman SV. (2003). Have insulin, will fly: Diabetes management during air travel and time zone adjustment strategies. Clin Diabetes 21:82-85.

Choi YH, and Lee MG. (2012). Pharmacokinetic and pharmacodynamic interaction between nifedipine and metformin in rats: Competitive inhibition for metabolism of nifedipine and metformin by each other via CYP isozymes. Xenobiotica 42: 483-495.

Cornish A, and Chase HP. (2012). Navigating airport security with an insulin pump and/or sensor. Diabetes Technol Ther 14:984-985.

Cranston I, Lomas J, Maran A, Macdonald I, and Amiel SA. (1994). Restoration of hypoglycaemia awareness in patients with long-duration insulin-dependent diabetes. Lancet 344: 283-287.

Dagogo-Jack S, Rattarasarn C, and Cryer PE. (1994). Reversal of hypoglycemia unawareness, but not defective glucose counterregulation, in IDDM. Diabetes 43:1426-1434.

de Mol P, de Vries ST, de Koning EJ, Gans RO, Bilo HJ, and Tack CJ. (2014). Physical activity at altitude: Challenges for people with diabetes: A review. Diabetes Care 37:2404-2413.

de Mol P, de Vries ST, de Koning EJP, Gans ROB, Tack CJ, and Bilo HJG. (2011). Increased insulin requirements during exercise at very high altitude in type 1 diabetes. Diabetes Care 34:591-595.

de Mol P, Fokkert MJ, de Vries ST, de Koning EJ, Dikkeschei BD, Gans RO, Tack CJ, and Bilo HJ. (2012). Metabolic effects of high altitude trekking in patients with type 2 diabetes. Diabetes Care 35:2018-2020.

de Mol P, Krabbe HG, de Vries ST, Fokkert MJ, Dikkeschei BD, Rienks R, Bilo KM, and Bilo HJ. (2010). Accuracy of handheld blood glucose meters at high altitude. PLoS One 5:e15485.

Diabetes UK. (2013). How do I manage crossing time zones? Available at https://www.diabetes.org.uk/FAQ/Travel-questions (accessed October 5, 2018).

Endo Y, Suzuki M, Yamada H, Horita S, Kunimi M, Yamazaki O, Shirai A, Nakamura M, Iso-ON, Li Y, Hara M, Tsukamoto K, Moriyama N, Kudo A, Kawakami H, Yamauchi T, Kubota N, Kadowaki T, Kume H, Enomoto Y, Homma Y, Seki G, and Fujita T. (2011). Thiazolidinediones enhance sodium-coupled bicarbonate absorption from renal proximal tubules via PPAR $\gamma$ dependent nongenomicsignaling. Cell Metab 13:550-561.

Fink KS, Christensen DB, and Ellsworth A. (2001). Effect of high altitude on blood glucose meter performance. Diabetes Technol Ther 4:627-635.

Gallen I. (2005). The management of insulin treated diabetes and sport. Pract. Diabetes Int 22:307-312.

Galloway JA, and Chance RE. (1994). Improving insulin therapy: Achievements and challenges. Horm Metab Res 26:591598.

Ganie MA, Koul S, Razvi HA, Laway BA, and Zargar AH. (2012). Hyperglycemic emergencies in Indian patients with diabetes mellitus on pilgrimage to Amarnathji yatra. Indian $\mathbf{J}$ Endocrinol Metab 16 (Suppl1):S87-S90.

Gautier J-F, Bigard AX, Douce P, Duvallet A, and Cathelineau G. (1996). Influence of simulated altitude on the performance of five blood glucose meters. Diabetes Care 19:1430-1433.

Geddes J, Schopman JE, Zammitt NN, and Frier BM. (2008). Prevalence of impaired awareness of hypoglycaemia in adults with Type 1 diabetes. Diabet Med 25:501-504.
Ginsberg BH. (2009). Factors affecting blood glucose monitoring: Sources of errors in measurement. J Diabetes Sci Technol 3:903-913.

Giordano BP, Thrash W, Hollenbaugh L, Dube WP, Hodges C, Swain A, Banion CR, and Klingensmith GJ. (1989). Performance of seven blood glucose testing systems at high altitude. Diabetes Educ 15:444-448.

Hargett NA, Ritch R, Mardirossian J, Kass MA, and Podos SM. (1977). Inadvertent substitution of acetohexamide for acetozolamide. Am J Ophthalmol 84:580-583.

Haupt A, Berg B, Paschen P, Dreyer M, Haring HU, Smedegaard J, and Matthaei S. (2005). The effects of skin temperature and testing site on blood glucose measurements taken by modern blood glucose monitoring device. Diabetes Technol Ther 7:597-601.

Heinemann L, Weyer C, Rauhaus M, Heinrichs S, and Heise T. (1998). Variability of the metabolic effect of soluble insulin and the rapid-acting insulin analog insulin aspart. Diabetes Care 21:1910-1914.

Hun Lee J, Choi PC. (2011). Comparison of methazolamide and acetazolamide for prevention of acute mountain sickness in adolescents. J Korean Soc Emerg Med 22:2011.

International Society of Travel Medicine. (2013). Available at http://www.istm.org/AF_CstmClinicDirectory.asp (accessed October 5, 2018).

Johnson ST, Robert C, Bell GJ, Bell RC, Lewanczuk RZ, and Boulé NG. (2008). Acute effect of metformin on exercise capacity in active males. Diabetes Obes Metab 10:747754.

Kalson NS, Davies AJ, Stokes S, Frost H, Whitehead AG, Tyrrell-Marsh I, and Earl MD. (2007). Climbers with diabetes do well on Mount Kilimanjaro. Diabet Med 24:1496.

Kenny GP, Yardley J, Brown C, Sigal RJ, and Jay O. (2010). Heat stress in older individuals and patients with common chronic diseases. CMAJ 182:1053-1060.

Killian RB, Nishimoto GS, and Page JC. (1998). Foot and ankle injuries related to rock climbing. The role of footwear. J Am Podiatr Med Assoc 88:365-374.

King BR, Goss PW, Paterson MA, Crock PA, and Anderson DG. (2011). Changes in altitude cause unintended insulin delivery from insulin pumps. Diabetes Care 34:1932-1933.

Koivisto VA, and Felig P. (1978). Effects of leg exercise on insulin absorption in diabetic patients. N Engl J Med 298:7983.

Küpper T. (2010). Sports climbing with diabetes mellitus [German: Sportkletternbei diabetes mellitus]. In: Moderne Berg- und Höhenmedizin. T Küpper, K Ebel, and U Gieseler, eds. GentnerVerlag, Stuttgart, Germany. pp. 569-570.

Küpper T, Morrison AB, Gieseler U, and Schöffl VR. (2009). Sport climbing with pre-existing cardio-pulmonary medical conditions. Int J Sports Med 30:395-402.

Lazarus B, Wu A, Shin JI, Sang Y1, Alexander GC, Secora A, Inker LA, Coresh J1, Chang AR, and Grams ME. (2018). Association of metformin use with risk of lactic acidosis across the range of kidney function: A community-based cohort study. JAMA Intern Med 178:903-910.

Leal C. (2005). Going high with type 1 diabetes. High Alt Med Biol 6:14-21.

Litch JA. (1996). Drug-induced hypoglycemia presenting as acute mountain sickness, after mistaking acetohexamide for acetazolamide. Wilderness Environ Med 7:232-235.

Lock JP, Brazg R, Bernstein RM, Taylor E, Patel M, Ward J, Alva S, Chen T, Welsh Z, Amor W, Bhogal C, and Ng R. (2011). Performance of a new test strip for freestyle blood glucose monitoring systems. Diabetes Technol Ther 13:1-10. 
Luks AM, Johnson RJ, and Swenson ER. (2008). Chronic kidney disease at high altitude. J Am Soc Nephrol 19:2262-2271.

MacDonald MJ. (1987). Postexercise late-onset hypoglycemia in insulin-dependent diabetic patients. Diabetes Care 10:584 588.

Mader TH, and Tabin G. (2003). Going to high altitude with preexisting ocular conditions. High Alt Med Biol 4:419-430.

Melvin A, and George J. (2016). A descriptive study of hot aches: A previously unreported winter climbing phenomenon. Sports Med Open 2:36-40.

Mieske K, Flaherty G, and O'Brien T. (2010). Journeys to high altitude-Risks and recommendations for travelers with preexisting medical conditions. J Travel Med 17:48-62.

Milledge JS, and Kupper T. (2008). People with pre-existing conditions going to the mountains. Consensus Statement of the UIAA Medical Commission. The International Mountaineering and Climbing Federation. Available at: www.theuiaa.org/ medical_advice.html (accessed October 5, 2018).

Miller SC. (2015). Diabetic ketoacidosis and acute mountain sickness: Case report and review of treatment options in type 1 diabetes mellitus. Wilderness Environ Med 26:185-188.

Mohajeri S, Perkins BA, Brubaker PL, and Riddell MC. (2015). Diabetes, trekking and high altitude: Recognizing and preparing for the risks. Diabet Med 32:1425-1437.

Monthly Index of Medical Specialities (MIMS). (2013). Insulins. In: C Harman, ed. Haymarket Business Media, London, United Kingdom. p. 402.

Moore K, Thompson C, and Hayes R. (2001a). Diabetes and extreme altitude mountaineering. Br J Sports Med 35:83.

Moore K, Vizzard N, Coleman C, McMahon J, Hayes R, and Thompson CJ. (2001b). Extreme altitude mountaineering and type 1 diabetes; the Diabetes Federation of Ireland Kilimanjaro Expedition. Diabet Med 18:749-755.

Morrison AB, and Schöffl VR. (2007). Physiological responses to rock climbing in young climbers. Br J Sports Med 41:852-861.

Mountains for Active Diabetics. (2013). Available at https:// www.facebook.com/groups/mountainmad/; http://diabetic.fri endsinhighplaces.org/ (accessed October 5, 2018).

Mustafa OG, Pender S, Martin V, Hale S, Emms R, Brookes P, Blankenberg $\mathrm{H}$, and Claase A. (2015). The use of safety checklist during climbing challenge up Mount Kilimanjaro with 19 participants with Type 1 diabetes: P556. Diabet Med 32:200-207.

Nazar CE, Echevarría GC, Lacassie HJ, Flores RA, and Muñoz HR. (2011). Effects on blood glucose of prophylactic dexamethasone for postoperative nausea and vomiting in diabetics and non-diabetics. Rev Med Chil 139:755-761.

Oberg D, and Ostenson CG. (2005). Performance of glucose dehydrogenase-and glucose oxidase based blood glucose meters at high altitude and low temperature. Diabetes Care 28:1261.

Olateju T, Begley J, Flanagan D, and Kerr D. (2012). Effects of simulated altitude on blood glucosemeter performance: Implications for in-flight blood glucose monitoring. J Diabetes Sci Technol 6:867-874.

Olson LA, Miller DR, Goswami A, McAskill AC, and Newman WP. (1991). Inadvertent administration of acetohexamide instead of acetazolamide. Ann Pharmacother 25:100.

Panofsky D. (2003). Handling type 1 diabetes in the mountains: Considerations for the diabetic climber. In: Health \& Height. Proceedings of the 5th World Congress on Mountain Medicine and High Altitude Physiology. G Viscor, A Ricart, and C Leal, eds. Universitat de Barcelona Publicacions, Barcelona, Spain.

Pavan P, Sarto P, Merlo L, Casara D, Ponchia A, Biasin R, Noventa D, and Avogaro A. (2003). Extreme altitude moun- taineering and type 1 diabetes: The Cho Oyu alpinisti in Alta Quota expedition. Diabetes Care 26:3196-3197.

Pavan P, Sarto P, Merlo L, Casara D, Ponchia A, Biasin R, Noventa D, and Avogaro A. (2004). Metabolic and cardiovascular parameters in type 1 diabetes at extreme altitude. Med Sci Sports Exerc 36:1283-1289.

Pecchio O, Maule S, Migliardi M, Trento M, and Veglio M. (2000). Effects of exposure at an altitude of $3,000 \mathrm{~m}$ on performance of glucose meters. Diabetes Care 23:129-131.

Perry E, and Gallen IW. (2009). Guidelines on the current best practice for the management of type 1 diabetes, sport and exercise. Pract Diabetes Int 26:116-123.

Peyser T, Dassau E, Breton M, and Skyler JS. (2014). The artificial pancreas: Current status and future prospects in the management of diabetes. Ann N Y Acad Sci 1311:102-123.

Pharmacy Retailing Limited. (2010). DIAMOX Acetazolamide. New Zealand Data Sheet, Auckland, New Zealand.

Public Health England. (2016). PHE Bulletin. New Diabetes Prevalence Data. HM Gov.UK, London. Available at: https:// www.gov.uk/government/news/38-million-people-in-englandnow-have-diabetes (accessed October 5, 2018).

Raab EL. (1979). Substitution of acetohexamide for acetazolamide. Am J Ophthalmol 87:848-849.

Richards P, and Hillebrandt D. (2013). The practical aspects of insulin at high altitude. High Alt Med Biol 14: 197-204.

Rutzen AR, and Weiss JS. (1993). Substitution of acetohexamide for acetazolamide. Am J Ophthalmol 116:379-380.

Sabb PC, and Allen JC. (1999). Acetohexamide-acetazolamide mix-up during emergency treatment. Am J Health Syst Pharm 56:2463.

Salpeter SR, Greyber E, Pasternak GA, and Salpeter EE. (2010). Risk of fatal and nonfatal lactic acidosis with metformin use in type 2 diabetes mellitus. Cochrane Database Syst Rev 1: CD002967.

Scalzo RL, Paris HL, Binns SE, Davis JL, Beals JW, Melby CL, Luckasen GJ, Hickey MS, Miller BF, Hamilton KL, and Bell C. (2017). Ergogenic properties of metformin in simulated high altitude. Clin Exp Pharmacol Physiol 44:729-738.

Schöffl V, and Küpper T. (2013). Feet injuries in rock climbers. World J Orthop 4:218-228.

Schöffl V, and Winkelmann HP. (1999). [Foot deformations in sport climbers] Fußdeformitäten bei Sportkletterern. D Z Sportmed 50:73-76.

Sener A, Jijakli H, ZahediAsl S, Courtois P, Yates AP, and Meuris S. (2007). Possible role of carbonic anhydrase in rat pancreatic islets: Enzymatic, secretory, metabolic, ionic, and electrical aspects. Am J Physiol Endocrinol Metab 292:E1624E1630.

Shlim DR, and Gallie J. (1992). The causes of death among trekkers in Nepal. Int J Sports Med 13 (Suppl 1):S74-S76.

Simpson RW, Nicholson GC, Proietto J, Sarah A, Sanders KM, Phillips G, Chambers J, MacGinley R, Orford N, Walder K, Krippner G, Skoff K, and Wacher VJ. (2014). Efficacy and safety of oral methazolamide in patients with type 2 diabetes: A 24-week, placebo-controlled, double-blind study. Diabetes Care 37:3121-3123.

Stickelmeyer MP, Graf CJ, Frank BH, Ballard RL, and Storms SM. (2000). Stability of U-10 and U-50 dilutions of insulin lispro. Diabetes Technol Ther 2:61-66.

Swenson E. (2014). Safety of carbonic anhydrase inhibitors. Expert Opin Drug Saf 13:459-472.

Thomas M, Sherwin RS, Murphy J, and Kerr D. (1997). Importance of cerebral blood flow to the recognition of and physiological responses to hypoglycemia. Diabetes 46:829-833. 
Valletta JJ, Chipperfield AJ, Clough GF, and Byrne CD. (2012). Metabolic regulation during constant moderate physical exertion in extreme conditions in Type 1 diabetes. Diabet Med 29:822-826.

Van de Putten EP, and Snijder CJ. (2001). Shoe design for prevention of injuries in sport climbing. Appl Ergon 32:379-387.

Vimalavathini R, and Gitanjali B. (2009). Effect of temperature on the potency \& pharmacological action of insulin. Indian $\mathbf{J}$ Med Res 130:166-169.

Visconti L, Cernaro V, Ferrara D, Costantino G, Aloisi C, Amico L, Chirico V, Santoro D, Noto A, David A, Buemi M, and Lacquaniti A. (2016). Metformin-related lactic acidosis: Is it a myth or an underestimated reality? Ren Fail 38:1560-1565.

WADA. (2017). Prohibited list. 2017. Available at: https://www .wada-ama.org/en/media/news/2016-09/wada-publishes-2017prohibited-list (accessed October 5, 2018).

Wild S, Roglic G, Green A, Sicree R, and King H. (2004). Global prevalence of diabetes: Estimates for the year 2000 and projections for 2030. Diabetes Care 27:1047-1053.

Wright AD, Bradwell AR, Fletcher RF. (1994). Methazolamide and acetazolamide in acute mountain sickness. Aviat Space Environ Med 54:619-621.

Wu TY, Ding SQ, Liu JL, Yu MT, Jia JH, Chai ZC, Dai RC, Zhang SL, Li BY, Pan L, Liang BZ, Zhao JZ, Qi de T, Sun YF, and Kayser B. (2007). Who should not go high: Chronic

\section{Appendix 1. Case Vignette}

One of the authors of this article was a previously fit and experienced 42-year-old mountaineer when diagnosed as suffering from late onset type 1 diabetes 5 months before departing on an expedition attempting to climb Everest. He had a good theoretical knowledge of his problem, but had little time to gain practical experience of insulin use in high mountain terrain due to the pressures leading up to an expedition departure.

At the base camp, the night before a predawn departure through the Khumbu icefall, he had an unexplained hypoglycemic episode (capillary glucometer reading at $5400 \mathrm{~m}$ of $3.2 \mathrm{mmol} / \mathrm{L}$ ) that required self-administered rescue carbohydrate with resultant rebound hyperglycemia, and the apparent need for additional insulin before departure.

The conditions were clear, but very cold as he faced sustained exercise in hypoxia interspersed with short bursts of disease and work at altitude during construction of the Qinghai-Tibet railroad. High Alt Med Biol 8:88-107.

Xue L, and Mikkelsen KH. (2013). Dose accuracy of a durable insulin pen with memory function, before and after simulated lifetime use and under stress conditions. Expert Opin Drug Deliv 10:301-306.

Yardley JE, Stapleton JM, Carter MR, Sigal RJ, and Kenny GP. (2013). Is whole-bodythermoregulatory function impaired in type 1 diabetes mellitus? Curr Diabetes Rev 9:126-136.

Zarkovic M, Beleslin B, Ciric J, Penezic Z, Stojkovic M, Trbojevic B, Drezgic M, and Savic S. (2008). Glucocorticoid effect on insulin sensitivity: A time frame. J Endocrinol Invest 31:238-242.

Address correspondence to: David Hillebrandt, $M B, B S$ Derriton House Holsworthy EX22 6JX England

E-mail: dh@hillebrandt.org.uk

Received April 3, 2018; accepted in final form August 20, 2018.

increased exertion on the fixed ladders. Hypoglycemic awareness was intact, but appreciation of symptoms may have been blunted by the environment, the previous night's hypoglycemic event, and some degree of anxiety. His usual hypoglycemic symptoms of agitation, hunger, fatigue, and reduced dexterity were initially abolished by consumption of emergency carbohydrate in various jacket pockets, but, later in the climb, when these symptoms worsened, all easily accessible stocks had been exhausted. He had to stop in a particularly dangerous part of the icefall, exposed to daunting seracs, to enable him to retrieve additional reserves from deep within his rucksack. On improvement, some minutes later, he was able to climb the nearby ladder to join his companions who had sensibly decided to continue to a place of relative safety. After a recovery period, they were then able to continue the ascent to Camp 1 without further incident. 